- Tongue and lip piercings are seen with increasing frequency in dental practice.

- A variety of complications involving these ornaments (some even life-threatening) have been described.

- Clinicians should discuss body piercing in the context of providing routine anticipatory guidance to patients.

- Clinicians should educate patients about safer piercing strategies to help minimise associated health risks.

\title{
Dental and oral complications of lip and tongue piercings
}

\author{
R. J. G. De Moor, ${ }^{1}$ A. M. J. C. De Witte, ${ }_{1}^{2}$ K. I. M. Delmé, ${ }^{3}$ M. A. A. De Bruyne, ${ }_{1}^{4}$ G. M. G. Hommez ${ }^{5}$ and D. Goyvaerts ${ }^{6}$
}

Piercing of the tongue and perioral regions is an increasingly popular expression of body art, with more patients coming in for a routine check-up with tongue and/or lip piercings. Several complications of oral piercing have been reported, some of which are life-threatening. In the present clinical survey the prevalence of both tongue and lip piercing complications in oral health was assessed in a group of 50 patients. The most common dental problem registered was chipping of the teeth, especially in association with tongue piercing. Gingival recession was seen as a result of lip piercing with studs. Postprocedural complications included oedema, haemorrhage and infection. Therefore, dentists and oral and maxillofacial surgeons should be given more authority to advise patients with oral and facial piercings or those who plan to acquire this type of body art.

Body piercing is defined as "penetration of jewellery into openings made in body areas such as eyebrows, helix of the ears, lips, tongues, nose, navel, nipples, and genitals ${ }^{\prime 1,2}$ and is a cultural practice that dates back to antiquity. ${ }^{1}$ It is only during the last decade that the art of body piercing and body modification attained popularity in Western Society. ${ }^{3,4}$ Gauntlet, a chain of piercing shops located in California, New York and Paris, reported carrying out at least 30,000 new piercings per year in the late 1990s. ${ }^{5}$

Of significance to the dental profession is the increasing popularity of tongue and lip piercings, which is the insertion of jewellery into soft oral tissues including the lips, cheeks and tongue. ${ }^{6}$ Rarely, it may

\footnotetext{
1"Professor, Head of Department, Department of Operative Dentistry and Endodontology, Ghent University, Ghent University Hospital, Dental School, De Pintelaan 185, B9000 Gent, Belgium; ${ }^{2-5}$ Assistant Professors, Department of Operative Dentistry and Endodontology, Ghent University, Ghent University Hospital, Dental School, De Pintelaan 185, B-9000 Gent, Belgium.

*Correspondence to: Professor Roeland De Moor Email: roeland.demoor@ugent.be
}

\section{Refereed Paper}

Accepted 15 July 2005

doi: 10.1038/sj.bdj4812852

๑ British Dental Journal 2005; 199: 506-509 also involve other oral sites, such as the uvula. $^{7}$ It appears that the tongue is the most prevalent oral piercing site, typically pierced in the midline and just anterior to the lingual frenum. ${ }^{8}$ A review of medical and dental literature revealed oral/dental and medical complications arising from tongue piercings in particular. Most of this information, however, was obtained from case reports dealing with a limited number of patients.

The oral and dental complications associated with tongue piercings can be categorised as acute (or early) and late (or chronic). ${ }^{8}$ A number of acute complications appear to be common; these include swelling of the tongue and pain; ${ }^{6,9}$ changes of speech, swallowing and mastication after placement of the ornament;2,6,7,10,11 and allergy to the metals when the piercing is not of the best quality or when it contains metals such as nickel. ${ }^{2,6}$ Less common acute symptoms were an increased salivary flow; ${ }^{11-13}$ generation of a galvanic current between barbell and metallic dental restorations: ${ }^{13}$ severe infection; ${ }^{12-15}$ critical airway compromise after central tongue piercing; ${ }^{16}$ and prolonged haemorrhage. ${ }^{17}$ Late and chronic complications refer to traumatic injury to the teeth such as chipping, fracturing of teeth and restorations and pulpal damage; $6,11,13$ trauma to the gingiva; ${ }^{13,18,19}$ localised tissue overgrowth;20,21 bifid tongue; ${ }^{22}$ persistent difficulties in oral functions; ${ }^{10,11}$ and swallowing of the device or device parts. ${ }^{13,23}$ Other findings that have been presented in case reports included the transmission of systemic infections such as hepatitis B, tetanus and HIV; $2,7,9$ the development of a cerebellar brain abscess as a result of an infection after the piercing procedure; ${ }^{24}$ endocarditis due to Neisseria mucosa ${ }^{25}$ and Heamophilus aphrophilus ${ }^{26}$ after tongue piercing; haemorrhage with great concern in medically compromised patients; ${ }^{27}$ and ornaments becoming embedded. ${ }^{28,29}$

As far as lip piercings are concerned, it appears that there are fewer problems. Gingival trauma and recession in relation to lip studs have been described. ${ }^{30,31}$

As the prevalence of piercings is clearly growing, the dental profession can anticipate an increase in associated dental complications. We evaluated the oral situation of 50 patients with tongue and/or lip piercings in order to clarify the risks, complications and dental implications of such procedures. 


\section{CASE STUDIES}

The oral and peri-oral situation of 50 patients (37 female, 13 male), with and without acute symptoms, was clinically and radiographically evaluated during 2002 and 2003. None of the patients came to the dental office with complications immediately after the piercing procedure. Informed consent was obtained from all patients participating in this study.

Objective features, such as visual damage to the teeth, gingival and mucosal injury, developing infection, skin irritation, noticeably increased salivary flow and allergy to the metal were scored. The buccal (lip piercings) and lingual (tongue piercings) gingival margins of the anterior teeth were evaluated for periodontal lesions by means of a periodontal probe. In this respect, it should also be mentioned that during the collection of this information as a part of the general anamnesis, enquiries were made regarding participation in contact sports and/or previous trauma in order to verify whether damage to the teeth was due to piercing or not.

The patients were questioned about subjective symptoms, such as the impairment of speech, swallowing and mastication. They were also questioned about the complications immediately after piercing.

Table 1 shows the sex and age distribution of the patient sample: most of the piercings were seen in the 16-20 and 2125 age groups, and piercings occurred most frequently in females under 25 years of age. Tongue piercings were seen in 47 patients: 40 piercings of the barbell-type (a bar with two balls) and seven of the labrette type (a ball on the ventral site of the tongue and a flat end on the dorsal side of the tongue). Lip piercings were seen in eight patients: four labrettes (flat end of the labrette on the mucosal side of the lip), one barbell and three lip rings. Only five patients had both a tongue and a lip piercing (two had a tongue barbell as well as a lip labrette; two had a tongue barbell as well as a lip ring; one had a barbell in both tongue and lip).

All tongue piercings, the lip labrettes/barbell and one lip ring were carried out in a 'Body-art-studio', whereas one of the lip

\begin{tabular}{|c|c|c|}
\hline Age & $\begin{array}{l}\text { Number } \\
\text { (male/female) }\end{array}$ & Per cent \\
\hline $12-15$ & $3(1,2)$ & 6 \\
\hline $16-20$ & $24(5,19)$ & 48 \\
\hline $21-25$ & $15(3,12)$ & 30 \\
\hline 30-35 & $5(2,3)$ & 10 \\
\hline $35-40$ & $2(1,1)$ & 4 \\
\hline$>40$ & $1(1,0)$ & 2 \\
\hline Total & $50(13,37)$ & 100 \\
\hline
\end{tabular}

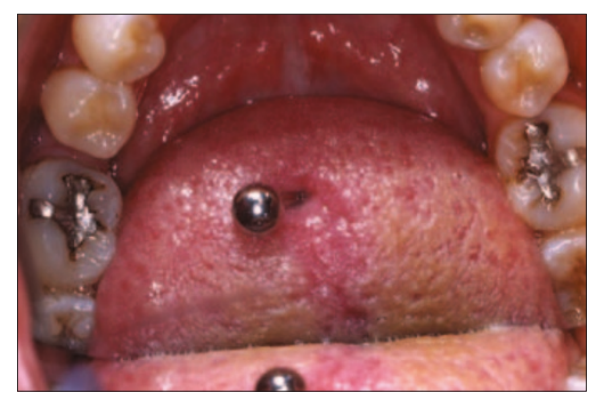

Fig. 1 Tear in the tongue in association with a tongue piercing in a 24-year-old male

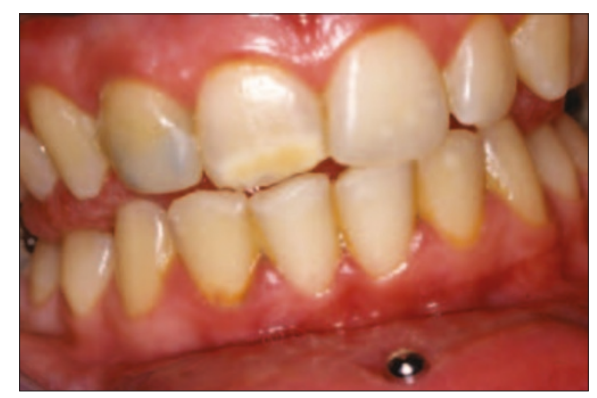

Fig. 2 Chipping of the maxillary incisors due to the presence of a lip piercing (barbell type) in a 25year-old female. According to the patient the resin composite restoration in the maxillary right lateral incisor had already been replaced two years earlier due to fracture and at that time it was chosen to restore the tooth with resin composite and parapulpal pins in order to improve retention

rings was placed by a jeweller and one by a friend.

Table 2 illustrates the data regarding the oral implications of the tongue and lip piercings. The average length of time since piercing was 12.6 months. Of the 50 patients only five were seeking immediate dental care due to cracked teeth (two) or the loss of tooth substance caused by a crack (three). One of these cracks with loss of tooth substance was accompanied by an extensive and acute abscess of the right upper first molar. Patients were also asked for complications or healing problems

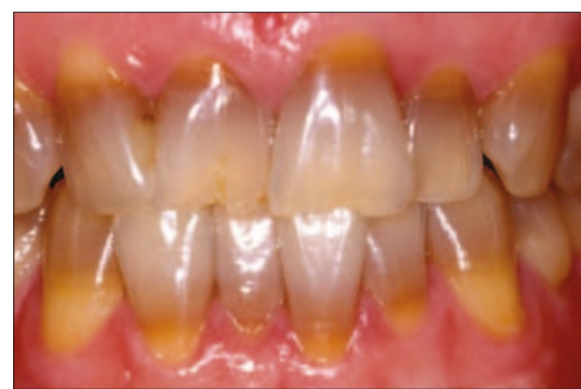

Fig. 3 Chipping and abrasion in maxillary and mandibulary front teeth due to the interposition of a lip piercing (22-year-old male)

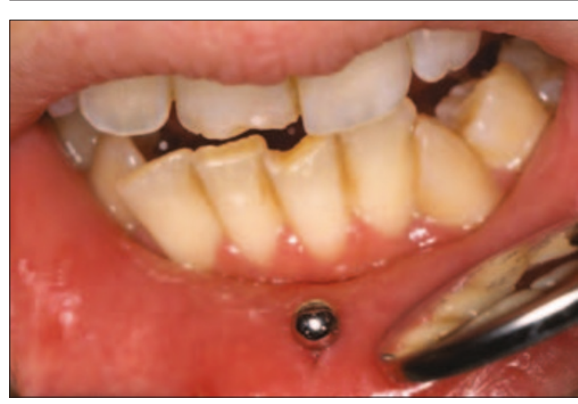
of a lip piercing in a 21-year-old female

immediately after piercing, which are listed in Table 3. In $74 \%$ of the patients ( $\mathrm{n}=$ 40) piercings healed without problems, the remaining $26 \%(n=13)$ mentioned complications such as infection (one - lip), swelling of the tongue (four) and lip (one) for more than one day, persisting pain (one lip/two tongue), haematoma (two lip), continued bleeding (one lip) and disturbed wound healing (one lip). Healing of these immediate complications was seen in all cases after removal of the piercing. Only one person consulted a physician (disturbed wound healing and infection of the lip as a result of non-professional piercing). Other problems mentioned were tearing of the tongue (one), eating problems (five after tongue piercing) and interference with speech (seven). Most of the
Fig. 4 Specific abrasion lesion due to interposition
Table 2 Data on the oral complications of the 47 tongue piercing and eight lip piercing cases

Type of complications
Cases requiring immediate professional medical and dental treatment

as a result of the piercings

Cases resulting in a split tooth with acute symptoms ie pain

Cases resulting in a cracked tooth with acute symptoms ie pain

Cases resulting in cracks with loss of tooth substance (cusp fracture) with acute symptoms

Cases resulting in cracks with loss of tooth substance (cusp fracture) without acute symptoms

Cases resulting in chipping of teeth

Tongue (47)

Lip (8)

Cases resulting in tooth abrasion

Cases with galvanic currents produced by the appliance

Cases developing infection

Cases resulting in gingival injury, gingival recession and attachment loss

Cases with noticeably increased salivary flow

Cases with persistent eating problem 


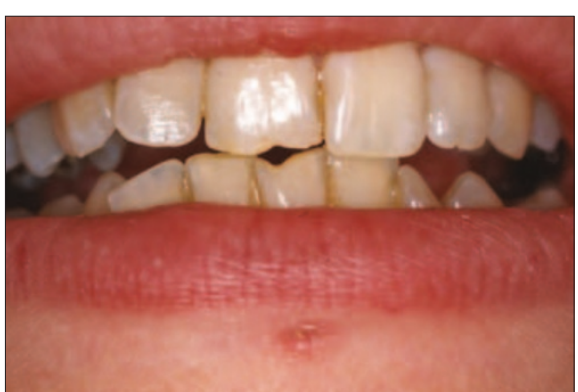

Fig. 5 The lower lip still shows signs of the presence of a lip piercing four weeks after removal of the ornament

participants, apparently, did not experience the eating problems and the interference with speech as a real problem but rather as a normal temporary consequence of piercing. The eating problems and the interference with speech disappeared in a period of a maximum two weeks. The tear in the tongue, however, had not been treated and resulted in a local scar (Fig. 1).

From Table 2 it appears that the most common problem in the long term was the damage of teeth with tooth substance loss i.e. chipping due to interferences during mastication and speech or intentional interposition (Figs 2 and 3), tooth abrasion (Figs 4 and 5) and fracture of cusps. Gingival injury was especially seen associated with lip piercings, resulting most frequently in a local gingival recession (three of the five cases) (Fig. 6); attachment loss was scored four times in association with tongue piercings and was registered by measuring with a periodontal probe at the lingual surface of the central mandibulary incisors (probing depths ranged from 5 to $7 \mathrm{~mm}$, with a mean of $5.7 \mathrm{~mm}$ ). Allergic reactions to the metal were not seen or mentioned.

Table 4 shows that the frequency of jewellery removal ranged from never to once every two days. Among those patients that never removed the tongue piercing, one presented with plaque and calculus around the barbell (Fig. 7). The

Table 3 Complications immediately after piercing

\begin{tabular}{lll}
\hline Complication & Tongue & Lip \\
\hline Infection & - & 1 \\
Swelling & 10 & 1 \\
$\quad(>1$ day) & $(4)$ & $(-)$ \\
Pain & 6 & 1 \\
$\quad(>1$ day) & $(2)$ & $(1)$ \\
Haematoma & - & 2 \\
Tear & 1 & - \\
Continued bleeding & - & 1 \\
Allergy & - & - \\
Disturbed wound healing & - & 1 \\
Eating problems & 5 & - \\
Interference with speech & 7 & -
\end{tabular}

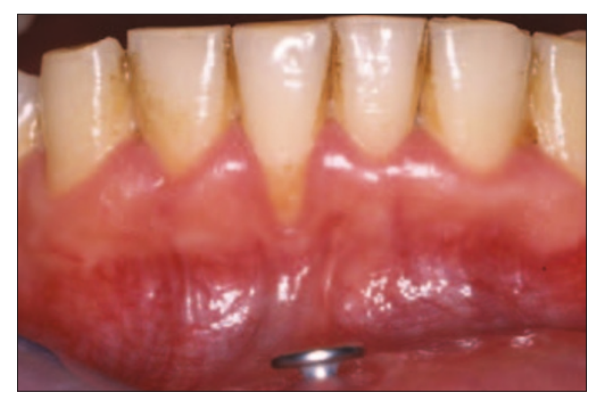

Fig. 6 Localised gingival recession due to scraping of a lip piercing in a 29-year-old male

average time the jewellery was left out was 15 minutes, ranging from the time of brushing the teeth and cleaning the piercings (five to 30 minutes). Tongue piercings were cleaned with a toothbrush and toothpaste (five) or with chlorhexidine (six). Two patients placed the piercing in hot boiling water for about 15 minutes. Two patients had swallowed a part of a barbell.

\section{DISCUSSION}

Oral and intraoral piercings have become a more prevalent form of body art and selfexpression in today's society. However, oral piercings, which involve the tongue (most common site), lips, cheeks, uvula or a combination of sites, have been implicated with a number of adverse oral and systemic conditions. ${ }^{32}$ In the present cases the effects of piercings on teeth, oral and perioral tissues, and general health were evaluated. In this patient sample tongue piercings were merely associated with the loss of tooth substance (chipping, cracks and fractures in the posterior region and tooth abrasion in the anterior region); lip piercings were especially associated with buccal gingival recession in the mandibular anterior region. These findings confirmed those of previous studies and a number of case reports. ${ }^{8,11,13,18-21,27,30,31}$ Other adverse outcomes secondary to oral piercing included salivary flow, gingival injury and recession at the lingual side of anterior mandibular teeth in association with tongue piercings, damage to teeth in the form of abrasion in association with lip piercings, scar-tissue formation, interference with speech, mastication or deglutition. Of the latter adverse outcomes the consequences of tongue piercings on the

\begin{tabular}{lll}
$\begin{array}{l}\text { Table } 4 \text { Range of frequency of jewellery } \\
\text { removed }\end{array}$ & $\begin{array}{l}\text { Number of cases } \\
\text { Tongue piercing } \\
(\mathbf{n}=\mathbf{4 7})\end{array}$ & $\begin{array}{l}\text { Lip piercing } \\
(\mathrm{n}=\mathbf{8})\end{array}$ \\
\hline & 32 & 3 \\
\hline Never & 10 & 1 \\
Once a day & 3 & 3 \\
Twice a day & 3 & 1 \\
$\begin{array}{l}\text { Once every } \\
\text { two days }\end{array}$ & 2 &
\end{tabular}

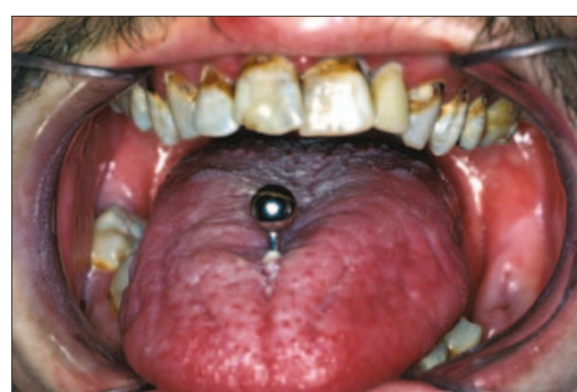

Fig. 7 Tongue piercing in an 18-year-old male without oral hygiene (plaque and calculus deposition around the bar of the tongue piercing)

lingual gingival margins of the mandibulary incisors should not be overlooked. As shown by Campbell et al. ${ }^{8}$ and Brooks et $a l .{ }^{19}$ severe attachment loss can develop even when gingival recession is minimal and it is therefore critical that patients with oral piercings routinely undergo comprehensive periodontal assessment.

Complications immediately after piercing were especially confined to injury of the weak tissues: swelling of the tongue resulting in masticatory difficulty and interference of speech as far as the tongue piercings were concerned; complications such as infection, swelling, haematoma, continued bleeding and disturbed wound healing as far as the lip was concerned. Only one of the patients in our sample consulted a physician and 20\% of the sample considered the short-term complications such as swelling, impediment of speech and masticatory difficulty normal. Mouthwash was in most of the cases recommended by the piercers when complications were to be expected. None of the present patients was aware of the fact that piercing has been identified as a possible vector for the transmission of blood borne viruses such as HIV, hepatitis (B,C, D and $\mathrm{G})$, herpes simplex and Epstein-Barr; ${ }^{32}$ and that complications after tongue piercing included bacterial infections (cases of infections with Staphylococcus aureus and Pseudomonas spp, ${ }^{9,33}$ neisseria endocarditis, ${ }^{30}$ Ludwig's angina ${ }^{3,12,17}$ and cerebral abscess $^{24}$ as a secondary complication have been described).

Despite performing invasive procedures, many body piercers do not have any formal education on sterilisation, effective skin care and proper infection control. Practitioners of body art appear to be aware of the need for infection control. They usually wear disposable gloves and use sterile or disposable instruments and autoclaved jewellery. . $^{3,13,21}$

From the present report and the survey of the literature it became clear that few people had serious problems related to tongue and lip piercing, notwithstanding the considerable damage and injury to both hard and soft oral tissues. However, 
in the context of a number of life-threatening complications, the practice of intraoral and perioral piercing should be opposed and legislation that requires parental consent regarding intraoral/ perioral piercing of minors should be supported. As the practice of body piercing continues, the profession needs to be aware of the sequelae that may arise as a result of piercing. Dentists should play an important role in convincing patients to remove the ornaments, as the limited concern about their oral health seems to be a common characteristic among these patients. Experience shows us that these patients seek treatment on an emergency basis or when forced by their family, and that they are reluctant to remove the ornament.

\section{CONCLUSION}

The presence of tongue and lip piercings implies a major risk for direct and indirect damage to both soft and hard oral tissues. Moreover, a number of life-threatening complications have been described in the literature.

As the practice of body piercing continues, the profession needs to be aware of the sequelae that may arise as a result of tongue and lip piercing. Dentists, oral and maxillofacial surgeons should play an important role in convincing patients to remove these ornaments, as a common characteristic among these patients seems to be the limited concern that they have about their oral health. The population should also be informed of the risks and complications of tongue and lip piercing.

1. Armstrong $\mathrm{M} \mathrm{L}$, Ekmark E, Brooks B. Body piercing promoting informed decision making. J Sch Nurs 1995; 112: 20-25.

2. Armstrong M L. You pierced what? Ped Nurs 1996; 22: 236-238.

3. Scully C, Chen M. Tongue piercing (oral body art). Br J MaxSurg 1994; 32:37-38.

4. Stirn A. Body piercing: medical consequences and psychological motivations. Lancet 2003; 361: 1205 1215.

5. Greif J, Hewit W, Armstrong M L. Tattooing and body piercing: body art practices among college students. Clin Nurs Res 1999; 8: 368-385.

6. Reichl R B, Dailey J C. Intraoral body piercing: a case report. Gen Dent 1996; 44: 346-347.

7. Price SS, Lewis M W. Body piercing involving oral sites. JADA 1997; 128: 1017-1020.

8. Campbell A, Moore A, Williams E, Stephens J, Tatakis D N. Tongue piercing: Impact of time and barbell stem length on lingual gingival recession and tooth chipping. J Perio 2002; 73: 289-297.

9. Chen $M$, Scully $C$. Tongue piercing: A new fad in body art. BrDent J 1992; 175: 87.

10. Farah CS, Harmon D M. Tongue piercing: case report and review of current practice. Austr Dent J 1998; 43: 387-389.

11. Maibaum W W, Margherita V A. Tongue piercing: A concern for the dentist. Gen Dent 1997; 45: 495-497.

12. Perkins C S, Meisner J, Harrison J M. A complication of tongue piercing. Br Dent J 1997; 182: 147-148.

13. De Moor R J G, De Witte A M J C, De Bruyne M A A. Tongue piercing and associated oral and dental complications. Endo Dent Trauma 2000; 16: 232237.

14. Koenig L, Carnes M. Body piercing, medical concerns with cutting-edge fashion. J Gen Intern Med 1999; 14:379-385.

15. Samantha $S$, Tweeten $M$, Rickman LS. Infectious complications of body piercing. Clin Infect Dis 1998; 265: 735-740

16. Keogh I J, O'Leary G. Serious complication of tongue piercing. J Laryngo/ Oto/2001; 15:374-381.
17. Hardee PS G F, Mallya L R, Hutchinson I L. Tongue piercing resulting in hypotensive collapse. Br Dent J 2000; 188: 657-658.

18. Dibart S, De Feo P, Surabian G et al. Oral piercing and gingival recession: review of the literature and a case report. Quint Int 2002; 33: 110-112.

19. Brooks J K, Hooper K A, Reynolds M A. Formation of mucogingival defects associated with intraoral and perioral piercing. JADA 2003; 134: 837-843.

20. Botha P J. Lingual piercing. SADJ 1998; 53: 453-454.

21. Theodossy T. A complication of tongue piercing. A case report and review of the literature. BrDent J 2003; 194: 551-552.

22. Fleming PS, Flood T R. Bifid tongue - a complication of tongue piercing. Br Dent J 2005; 198: 265-266.

23. Cheong $Y$ H. The fading links between tradition and oral health in Singapore. Int Dent J 1984; 34: 253256

24. Martinello R A, Cooney E L. Cerebellar brain abscess following tongue piercing. Clin Infect Dis 2003; 36: E32-E34.

25. Tronel $H$, Chaudemanche $H$, Pechier N, Doutrelant $L$, Hoen B. Endocarditis due to Neisseria mucosa after tongue piercing. Clin Microbiol Infect 2001; 7: 275276.

26. Akhondi H, Rahimi A R. Haemophilus aphrophilus endocarditis after tongue piercing. Emerg Infect Dis 2002; 8: 850-851.

27. Fehrenbach $\mathrm{M} J$. Tongue piercing and potential ora complications. J Dent Hyg 1998; 72: 23-25.

28. Mandal A, Mckinnell T, Berry R B. Retained tongue stud: an unusual complication of tongue piercing. $\mathrm{Br}$ J Past Surg: 55: 535-536.

29. Shacham R, Zaguri A, Librus H Z, Bar T, EliavE, Nahlieli 0 . Tongue piercing and its adverse effects. Oral Surg Oral Med Oral Pathol 2003; 95: 274-276.

30. Er N, Özkavak A, Berberoglu A, Yamalik N. An unusual cause of gingival recession: oral piercing. $J$ Periodontol 2000; 71: 1767-1769.

31. O'Dwyer J J, Holmes A. Gingival recession due to trauma caused by a lower lip stud. Br Dent J 2002; 192: 615-616.

32. American Dental Association. ADA Statement on Intraoral/Perioral Piercing. Accessed May 14, 1999. http://www.ada.org/prof/resource/positions/stateme nts/piercing.asp

33. Bassiouny M A, Deem L P, Deem T E. Tonque piercing: a restorative perspective. Quint Int 2001; 32:37-38. 